\title{
Julián Calvo Blanco: Un jurista masón del exilio español en México
}

\section{Julián Calvo Blanco: A freemason jurist from Spain exiled in Mexico}

Eva Elizabeth Martínez Chávez

El Colegio de Michoacán, México

elizabeth march@hotmail.com

Recepción: 25 de abril de 2019/Aceptación: 10 de junio de 2019

doi: https://doi.org/10.15517/rehmlac.v11i2.36069

\section{Palabras clave}

Guerra civil española; exilio; jurista; masonería; México.

\section{Keywords}

Spanish Civil War, exile, jurist, Freemasonry, Mexico.

\section{Resumen}

El artículo analiza la vida y obra de Julián Calvo Blanco, un jurista español exiliado en México tras la Guerra Civil española. En esta investigación se busca estudiar la relación que existió entre la masonería y el exilio español. A partir de archivos históricos mexicanos y españoles, reconstruimos los datos biográficos de Calvo Blanco, su vida en España antes del exilio, en México y su participación en la masonería, tanto en la española como en la mexicana. Esta información nos permite conocer la participación de la masonería mexicana en la llegada y la incorporación de no pocos masones españoles.

\section{Abstract}

This paper analyzes the life and work of Julián Calvo Blanco, a Spanish jurist exiled in Mexico after the Spanish Civil War, in order to study the relationship between Freemasonry and the Spanish exiles. Our research was based primarily on historical archives in Mexico and Spain thus gathering information on his life in Spain before exile, the voyage that brought him to Mexico, and his participation in Freemasonry in both countries. The details of his activities as a Mason increase our knowledge of Mexican Freemasonry's part in the arrival and incorporation of quite a few Spanish Masons. 


\section{Presentación}

La Guerra Civil Española (1936-1939) ha sido ampliamente estudiada desde diferentes frentes ${ }^{1}$. Los miles de españoles que llegaron a México a consecuencia de ese enfrentamiento armado también han generado mares de tinta que se han esparcido en publicaciones mexicanas y extranjeras. No obstante, aún hay lagunas que deben ser colmadas para conocer y comprender con mayor profundidad este fenómeno; siendo este el caso del tema que atañe al presente trabajo: la relación que existió entre la masonería y los juristas españoles exiliados en México.

Esta relación es importante, entre otras cuestiones, por la trascendencia que algunos de estos juristas tuvieron en España y en América. Varios de estos estudiosos fueron catedráticos en las universidades de la Península -el puesto más alto en la estructura universitaria-. Otros desempeñaron cargos políticamente importantes, aquí podemos contar a Mariano Ruiz-Funes, quien en 1931 fue elegido diputado a Cortes por Murcia. Ese mismo año fue nombrado vocal de la Comisión Jurídica Asesora del Ministerio de Justicia. Se desempeñó también como miembro de la Comisión Parlamentaria que redactó la Constitución de la Segunda República Española y, en 1936, fue elegido Diputado a Cortes por Bilbao $^{2}$. Otro jurista que se relacionó con la masonería y al que procesaron y sentenciaron por masón fue Felipe Sánchez-Román y Gallifa. Durante la II República también fue diputado en las Cortes Constituyentes de 1931 y encabezó el Partido Nacional Republicano. Durante su exilio en México Sánchez-Román impulsó la fundación del Instituto de Derecho Comparado de México, actual Instituto de Investigaciones Jurídicas de la Universidad Nacional Autónoma de México³.

En este sentido, considero importante desarrollar una línea de investigación que analice el papel que la masonería mexicana tuvo en la recepción e integración de los hermanos masones españoles en ese país americano. La empresa es complicada, pues no es fácil acceder a los documentos generados por la masonería. Conocedora de esta dificultad emprendí el trabajo de reconstruir la vida y obra de Julián Calvo Blanco, uno de los cientos de licenciados en derecho que colaboraron con el gobierno de la Segunda República y que, al ser derrotado el bando republicano, se trasladó a México, país en el que vivió una considerable parte de su largo exilio.

Las pretensiones de este trabajo son más bien modestas. El objetivo es proporcionar una noticia biográfica de Calvo Blanco, dar cuenta de sus actividades en España anteriores al exilio, así como los motivos que lo llevaron a dejar su país de nacimiento, los medios que utilizó para trasladarse a México, así como las actividades que realizó en dicho país

$1 \quad$ La Segunda República española fue un régimen democrático que inició en 1931 y culminó en 1939, con la pérdida de la Guerra Civil por los seguidores de la República y el triunfo del bando encabezado por el general Francisco Franco.

2 Eva Elizabeth Martínez Chávez, "Ruiz-Funes García, Mariano (1889-1953)", en Diccionario de catedráticos españoles de derecho. 1847-1943 (Madrid: Universidad Carlos III de Madrid: 2012), http://portal.uc3m.es/portal/page/portal/instituto figuerola/programas/phu/diccionariodecatedraticos/lcatedraticos/rfunes

3 Martínez Chávez, "Juristas masones del exilio republicano español en México", en Masonería y sociedades secretas en México, coords. José Luis Soberanes Fernández y Carlos Francisco Martínez Moreno (Ciudad de México: UNAM, Instituto de Investigaciones Jurídicas, 2018), 371-372, https://archivos.juridicas.unam.mx/www/bjv/libros/11/5147/14.pdf 
y, por último, el papel que jugó la masonería en su vida. Las fuentes para reconstruir esta historia de vida fueron bibliográficas, entrevistas y, principalmente, archivos históricos, tanto mexicanos como españoles.

El hecho de que Calvo Blanco haya sido uno de los pocos exiliados que dejó testimonio de su participación en la masonería fue decisivo al momento de elegirlo como objeto de estudio. Una importante fuente para este análisis fue una entrevista que concedió en 1979 a Concepción Ruiz-Funes, a la que, en 1981, se le incorporó un anexo realizado por Enriqueta Tuñón. Entre recuerdos y sinsabores, el entrevistado narró sus actividades en la masonería, en España y México. Son escasas cuatro páginas en las que quedó constancia de sus acciones como miembro de la masonería, pero es más de lo que he logrado localizar sobre otros juristas también exiliados en México y que pertenecieron a la masonería ${ }^{5}$, entre ellos su mentor Mariano Ruiz-Funes García ${ }^{6}$, Victoria Kent Siano ${ }^{7}$, Gabriel Bonilla Marín, Demófilo de Buen Lozano ${ }^{9}$ o Manuel Martínez Pedroso ${ }^{10}$.

\section{Información biográfica}

Julián Calvo Blanco nació en Murcia, España, el primero de febrero de $1909^{11}$. Sus padres fueron José Calvo y Consuelo Blanco ${ }^{12}$. Su padre, abogado, fue funcionario de la administración de justicia en Murcia. El propio Julián Calvo informó que su familia podría encuadrarse en la clase media, aunque sin poder precisar si media baja o alta; sin embargo, la situación familiar cambió drásticamente cuando murió la cabeza de su familia. En ese tiempo Julián contaba con escasos 15 años y, al quedar huérfano de padre, y como hijo mayor, quedó al frente de la familia, compuesta por su madre y dos hermanos menores que él. En esos años estudiaba el bachillerato en el Instituto de Murcia y tuvo que buscar la manera de resolver la parte económica y familiar de su casa. Con la responsabilidad familiar y la escasez económica, se vio en la necesidad de estudiar en su ciudad natal la carrera de Derecho ${ }^{13}$.

La ficha migratoria que se elaboró por el gobierno mexicano cuando Calvo realizó los trámites para ingresar a ese país permite conocer sus características físicas. Fue un hombre de estatura baja, medía un metro y cincuenta centímetros, de complexión delgada,

4 Instituto Nacional de Antropología e Historia (INAH), Archivo de la Palabra, Calvo Blanco, Julián, PHO/10/37. Entrevista a Julián Calvo, realizada en su domicilio particular de la ciudad de Madrid, por Concepción Ruiz-Funes, el día 5 de mayo de 1979 y anexo realizado por Enriqueta Tuñón los días 30 de noviembre y 3 de diciembre de 1981. En adelante se citará como Entrevista. Por este medio deseo agradecer a la doctora Dolores Pla Brugat (q. e. p. d.) su generosidad al mostrarme el contenido de este archivo, quede pues constancia de mi agradecimiento a una gran mujer e investigadora.

5 Para más información sobre estos juristas puede verse Martínez Chávez, "Juristas masones”, 365-384.

6 Sobre su actividad como masón véanse sus expedientes en el Centro Documental de la Memoria Histórica, en adelante CDMH, legajo 421-B, Expediente 1. Expediente personal de Mariano Ruiz-Funes García; y su proceso ante el juzgado especial número tres de Madrid del Tribunal Especial para la Represión de la Masonería y el Comunismo (TERMC), al cual se le asignó el número 33172.

7 CDMH, Legajo 664, Expediente 10. Expediente personal de Victoria Kent.

8 CDMH, Caja 75/1190; Legajo 201-A, Expediente personal número 3; TERMC, Legajo 184, Expedientes 9194 y 2897. Expedientes de Gabriel Bonilla Marín.

9 CDMH, Legajo 5, Expediente 4-A. Expediente personal de Demófilo de Buen Lozano.

10 CDMH, Legajo 88-A, Expediente 2. Expediente personal de Manuel Martínez Pedroso.

11 Estos datos se pueden encontrar en la Entrevista y en el Archivo General de la Nación de México, en adelante (AGN), Secretaría de Gobernación, Siglo XX, Departamento de Migración, Españoles, Caja 38, Expediente 40. Julián Calvo Blanco.

12 Archivo de la Dirección General de Costes de Personal y Pensiones Públicas (Clases Pasivas), en adelante ADGCPPP, Expedientes de Calvo Blanco, Julián y Vergara Flores, Eliana.

13 Entrevista. 
tez blanca, cabello negro, ojos "pardos", nariz recta, boca mediana y sin señas particulares visibles. Eran los años cuarenta del siglo pasado y declaró a las autoridades mexicanas ser soltero y de profesión abogado ${ }^{14}$.

Sobre la familia formada por Julián Calvo se sabe que contrajo matrimonio en el exilio, ya próximo a cumplir los 50 años. Unió su vida a la de Eliana Vergara Flores, psicóloga y profesora de inglés, el diez de julio de 1957. El enlace tuvo lugar en Santiago de Chile. Fue padre de dos hijos: José Julián, nacido el catorce de julio de 1958, y Enrique, quien llegó a este mundo el doce de noviembre de $1960^{15}$.

Calvo vivió para ver llegar el fin de los días de Francisco Franco, lo que le permitió regresar a su país de nacimiento para exhalar en él su último aliento. Murió en su domicilio en Madrid, el día veintiocho de febrero de 1986, cuando contaba con 77 años. La causa de su deceso se atribuyó a un -accidente vascular cerebral-. Sus restos mortales fueron incinerados y sus cenizas quedaron en "custodia familiar" ${ }^{16}$.

\section{La vida en España antes del exilio}

Julián Calvo estudió la licenciatura en Derecho en la Universidad de Murcia ${ }^{17}$. Una vez que consiguió titularse, solicitó a la Junta para Ampliación de Estudios (JAE) una pensión (1932), pues pretendía estudiar Derecho Penal en la Universidad de Munich durante dos años, bajo la dirección del profesor alemán Edmund Mezger ${ }^{18}$. En 1932 Mezger estaba recién incorporado a la Universidad de Munich y hacía poco que había aparecido su Tratado de Derecho Penal. Según indicó Calvo Blanco en su solicitud a la JAE, los profesores Luis Jiménez de Asúa y José Arturo Rodríguez Muñoz consideraban el tratado de Mezger como -de original concepción jurídica-y merecedor de una preferente atención por los estudiosos españoles ${ }^{19}$. En 1935, a escasos tres años de que Julián Calvo solicitara la pensión a la JAE, se publicó en España la traducción del Tratado de Derecho Penal de Mezger, y fue justamente el profesor Rodríguez Muñoz, discípulo de Jiménez de Asúa ${ }^{20}$, quien se encargó de trasladar sus páginas al español²1.

Pero regresemos a 1932. En ese entonces Calvo Blanco contaba con 24 años y ya había asistido a los cursos de doctorado en Derecho en la Universidad Central de Madrid (19291930)22. Después de sus clases de doctorado, durante el curso 1930-1931, se incorporó como profesor-ayudante en la cátedra de Derecho Penal en la Facultad de Derecho de la Universidad

\footnotetext{
14 AGN, Secretaría de Gobernación, Siglo XX, Departamento de Migración, Españoles, Caja 38, Expediente 40. Julián Calvo Blanco.

15 Cfr. Entrevista.

16 Información tomada del acta de defunción de Julián Calvo Blanco. En ADGCPPP, Expedientes de Calvo Blanco, Julián y Vergara Flores, Eliana.

17 Le expidieron el título el 4 de septiembre de 1931. Durante sus años de exilio también obtuvo el título de licenciado en Derecho por la Universidad Nacional Autónoma de México. El título le fue expedido el 25 de julio de 1952. Cfr. Entrevista.

18 Archivo Histórico de la Junta para Ampliación de Estudios, en adelante AHJAE, Expediente JAE/27-90. AHJAE, Expediente JAE/27-90.

20 Véase Eduardo Cebreiros Álvarez, “Rodríguez Muñoz, José Arturo (1899-1955)”, en Diccionario de catedráticos, http://portal. uc3m.es/portal/page/portal/instituto figuerola/programas/phu/diccionariodecatedraticos/lcatedraticos/rmunoz

21 Edmund Mezger, Tratado de Derecho Penal (Madrid: Editorial Revista de Derecho Privado, 1935).

22 AHJAE, Expediente JAE/27-90.
} 
de Murcia, -a propuesta y bajo la dirección del profesor Don Mariano Ruiz-Funes García - ${ }^{23}$. Poco a poco se empezaba a consolidar su lugar en la estructura universitaria, ya que, desde el 8 de diciembre de 1931, por Orden ministerial y a propuesta de la Junta de Facultad ${ }^{24}$, desempeñó interinamente las funciones del entonces auxiliar Antonio Reverte Moreno ${ }^{25}$.

Como profesor-ayudante se encargaba de sustituir en las clases de Derecho Penal al profesor-auxiliar y también al catedrático Mariano Ruiz-Funes. Con este último colaboró, en los primeros años de la década de los 30, en un trabajo monográfico que realizaban en la universidad sobre la progresión científica de la pena de muerte en España ${ }^{26}$. Calvo también se llegó a encargar de impartir cursillos prácticos en la cátedra de Derecho Penal, como el de Parte Especial del Derecho Penal y Los Delitos Contra las Personas ${ }^{27}$.

Además de las clases como ayudante y sus actividades en la universidad, se encontraba redactando la memoria que tenía que presentar para obtener el grado de doctor en Derecho, la que versaba sobre "La justicia criminal en la América prehispánica", trabajo que había comenzado bajo la dirección del catedrático Rafael Altamira y Crevea $^{28}$, con quien años después se reencontraría en el exilio mexicano. Así pues, en ese entonces Calvo Blanco era un joven ayudante en la Universidad de Murcia en plena escritura de su tesis doctoral y ya tenía conocimiento de varios idiomas. A la JAE declaró que, para 1932, ya conocía los idiomas francés, alemán y, parcialmente, el italiano, aunque para esa fecha no había residido en el extranjero ${ }^{29}$.

Durante la Segunda República también desempeñó varios cargos en el gobierno. En junio de 1932 fue designado secretario de la Agrupación de Jurados Mixtos de Ferrocarriles con residencia en Murcia. Este nombramiento fue respaldado con la firma del director general del trabajo, Francisco Largo Caballero ${ }^{30}$. En la entrevista que dio a Concepción RuizFunes mencionó que fue funcionario técnico-administrativo de la Diputación Provincial de Murcia $^{31}$ y que durante el año 1937 colaboró en la legación de España en Varsovia, como secretario particular de Mariano Ruiz-Funes ${ }^{32}$, cuando el catedrático universitario fue nombrado Encargado de Negocios de España en Varsovia (marzo-junio de 1937). Después de este encargo Ruiz-Funes fue nombrado Embajador de España en Bruselas, Bélgica (julio de 1937 a marzo de 1939$)^{33}$, a donde lo acompañó Calvo Blanco, aunque no por todo el periodo

23 AHJAE, Expediente JAE/27-90.

24 AHJAE, Expediente JAE/27-90.

25 AGA, (5) 1.3 31/2215, Expediente 33. Expediente personal de Julián Calvo Blanco como ayudante de clases prácticas de la Facultad de Derecho de la Universidad de Murcia. El propio Calvo mencionó que durante los años 1930-1939 fue profesor ayudante de Derecho Penal y Derecho Procesal en la Facultad de Derecho de la Universidad de Murcia. Esta información se conserva en la Entrevista ya mencionada. Sobre Reverte Moreno puede verse Manuel Martínez Neira y Julián Gómez de Maya, "Reverte Moreno, Antonio (1905-1981)", en Diccionario de catedráticos, http://portal.uc3m.es/portal/page/portal/instituto figuerola/programas/phu/diccionariodecatedraticos/lcatedraticos/revertemoreno

26 Este trabajó se publicó dos años después. Mariano Ruiz-Funes García, Progresión histórica de la pena de muerte en España (Madrid: Editorial Revista de Derecho Privado, 1934).

27 AHJAE, Expediente JAE/27-90. Según Yolanda Blasco y Saorín Pérez, también fue auxiliar de la Facultad de Derecho de la Universidad de Murcia. Yolanda Blasco Gil y Tomás Saorín Pérez, Las universidades de Mariano Ruiz-Funes: La lucha desde el exilio por la Universidad perdida (Murcia: Universidad de Murcia, 2014), 89.

28 AHJAE, Expediente JAE/27-90.

29 AHJAE, Expediente JAE/27-90.

30 Gaceta de Madrid, No. 188, de 6 de julio de 1932, Pág. 157.

31 Entrevista.

32 Entrevista.

33 Sobre Mariano Ruiz-Funes puede verse la tesis doctoral de Beatriz Gracia Arce, "Mariano Ruiz-Funes: intelectual y político (1923-1953). Aportación a la modernización del sistema liberal-democrático en España y proyección 
durante el cual el embajador permaneció en su encargo, ya que Calvo tuvo que volver a España para incorporarse al ejército. Como soldado de servicios auxiliares, se integró al Servicio de Justicia Militar ${ }^{34}$.

También se tienen noticias de su pertenencia a la Unión General de Trabajadores (UGT). Desde 1924 formó parte del Sindicato de Funcionarios de la Diputación de Murcia; fue vocal de esta agrupación antes de la Guerra, en marzo de 19345. Asimismo, sabemos que durante su vida estuvo afiliado a varias agrupaciones políticas: Acción Republicana en 1930; a Izquierda Republicana en 1934 y después de su exilio a Acción Republicana Española (1975) ${ }^{36}$.

En la España republicana ocupó diversos cargos directivos en las organizaciones municipales y provinciales, entre ellos Vice-presidente de la Agrupación de Murcia y Secretario del Consejo Provincial de Murcia. Formó parte del Secretariado Técnico de Justicia en el Consejo Nacional. Lo nombraron delegado en el Comité Provincial del Frente Popular de Murcia, desde febrero de 1936, habiendo desempeñado, entre otros, el cargo de secretario de dicho Frente Popular, durante los primeros meses de la Guerra Civil ${ }^{37}$.

En 1938 lo encontramos desempeñándose como teniente auditor en campaña del cuerpo jurídico militar de la República Española ${ }^{38}$. Posteriormente fue designado magistrado del Tribunal Central de Espionaje y Alta Traición (Barcelona) ${ }^{39}$, por renuncia de doña Julia Álvarez Resano ${ }^{40}$. Calvo Blanco antes de recibir este nombramiento se desempeñaba como juez de primera instancia e instrucción interino de Alberique, Valencia ${ }^{41}$. Años de trabajo se vieron truncados con la pérdida de la guerra y el posterior exilio.

Fueron décadas las que Calvo pasó lejos de su patria y al regresar encontró apoyos gubernamentales que beneficiaban a quienes habían colaborado con la Segunda República. Como abogado sabía conducirse por los vericuetos institucionales y se enteró que en esos años existía la opción de solicitar del gobierno español una pensión por los servicios prestados en las fuerzas armadas, por lo que solicitó dicha retribución.

internacional de su obra”, (Tesis de doctorado en Filosofía, Universidad de Murcia, 2013). También Julián Calvo escribió sobre su maestro el texto "Semblanza de Mariano Ruiz-Funes”, en Derecho consuetudinario y economía popular de la provincia de Murcia, Mariano Ruiz-Funes (Murcia: Editora Regional de Murcia, 1983). Un trabajo más en el que es posible encontrar información sobre este catedrático fue escrito por Martínez Chávez, "RuizFunes García, Mariano (1889-1953)”, 2012.

34 Entrevista.

35 Biblioteca del Instituto Nacional de Antropología e Historia (México), en adelante Biblioteca del INAH, Archivo del Comité Técnico de Ayuda a los Republicanos Españoles, Expediente 5455, Calvo Blanco, Julián.

36 Galo Sánchez Casado, Los altos grados de la masonería (Madrid: Ediciones Akal, 2009), 441.

37 Biblioteca del INAH, Archivo del Comité Técnico de Ayuda a los Republicanos Españoles, Expediente 5455, Calvo Blanco, Julián.

38 Al respecto véase la orden circular del Ministerio de Defensa Nacional, publicada en el No. 271 de la Gaceta de la República, correspondiente al día 28 de septiembre de 1938, Pág. 1456. Esta información también puede consultarse en su expediente del ADGCPPP, Expedientes de Calvo Blanco, Julián y Vergara Flores, Eliana.

39 Entrevista.

40 Julia Álvarez terminó sus días exiliada en México. Su ficha migratoria se puede consultar en AGN, Instituciones Gubernamentales: época moderna y contemporánea, Administración Pública Federal S. XX, Secretaría de Gobernación Siglo XX, Departamento de Migración (201), Españoles, Caja 012, Expediente 99. Álvarez Resano, Julia. Ingresó como asilada política. Ante las autoridades migratorias mexicanas declaró haber nacido en España en 1903, ser viuda y desempeñarse como abogada y profesora. Dio como referencia en México a la señora Carmen Guerra.

Gaceta de la República 248, 5 de septiembre de 1938, 1083. 
Después de analizar su solicitud, la Dirección General de Costes de Personal y Pensiones Públicas, Servicio de Pensiones Especiales, del Ministerio de Economía y Hacienda, determinó que una vez estudiada la legislación especifica, en este caso la ley 37/84 y el Real Decreto 1033/1985 $5^{43}$, así como las demás de pertinente aplicación al caso concreto, se reconoció que Julián Calvo Blanco "prestó servicios en las fuerzas armadas como teniente según nombramiento publicado en el Diario Oficial correspondiente al 28/09/1938", por lo que se consideró que tenía derecho a "la asistencia médico-farmaceutica y servicios sociales prestados por el régimen general de la seguridad social a los pensionistas afiliados a este, en el caso exclusivo de que no los tuviera ya por otro concepto"; también se hizo acreedor a "una pensión por importe igual al del mínimo de pensión de jubilación establecido por dicho régimen general en este ejercicio para los pensionistas del mismo con iguales circunstancias familiares que el interesado"; así como al uso de las distinciones determinadas en el anexo del Real Decreto 1033/85 y, "en los actos militares solemnes a que sea expresamente convocado, del correspondiente uniforme" ${ }^{44}$.

\section{El viaje a México}

El 27 de enero de 1939, ante la pérdida inminente de la Guerra Civil, Calvo Blanco salió por Figueras rumbo a Perpignan ${ }^{45}$; en el camino a Francia se encontró con un viejo amigo, José Luis Praza, gracias al cual consiguió del cónsul francés -un [sic] visa francés- en su pasaporte, cuando aún se encontraban en territorio español; así, a diferencia de miles de sus compatriotas pasó a Francia con sus papeles en regla, ostentando un pasaporte republicano y un visado francés temporal. De Perpignan se dirigió a París para trasladarse después a Bélgica, en donde se reunió nuevamente con Mariano Ruiz-Funes y su familia. Cuando concluyó la guerra en España residió en Bruselas y en La Panne. Durante ese tiempo, sus escasos medios de subsistencia los obtuvo del gobierno republicano en el exilio, de quien recibía un pago por su condición de magistrado, aun cuando por la situación no realizara esta actividad. Otro apoyo valioso fue el que le otorgó la familia Ruiz-Funes, pues durante un tiempo vivió "prácticamente en su casa" ${ }^{46}$.

Ya en plena Guerra Mundial se planteó la necesidad de emigrar a América, en primera instancia no pensó en viajar a México, por la gran cantidad de compatriotas que se habían instalado en ese país y pensando que ya eran demasiados españoles en México. Con esta idea en mente intentó viajar a Uruguay, en donde tenía un amigo; este viaje no logró concretarse debido a que el gobierno uruguayo le solicitó un certificado en el que demostrara que no tenía antecedentes penales, documento que naturalmente no pudo obtener del gobierno franquista. Aunque consiguió una visa para trasladarse a Colombia, al final decidió viajar a México con la ayuda de unos amigos que ya se encontraban en ese país ${ }^{47}$.

42 Ley 37/1984, de 22 de octubre. Trata sobre el reconocimiento de derechos y servicios prestados a quienes durante la Guerra Civil formaron parte de las Fuerzas Armadas, Fuerzas de Orden Público y Cuerpo de Carabineros de la República. Se puede consultar en Boletín Oficial el Estado 262, 1 de noviembre de 1984.

43 Real Decreto 1033/1985, de 19 de junio, desarrolla lo dispuesto por la Ley 37/1984, de 22 de octubre.

44 ADGCPPP, Expedientes de Calvo Blanco, Julián y Vergara Flores, Eliana.

45 Biblioteca del INAH, Archivo del Comité Técnico de Ayuda a los Republicanos Españoles, Expediente 5455, Calvo Blanco, Julián.

46 Entrevista.

47 Es posible que entre los amigos que lo ayudaron a su traslado a México se encontrara Lázaro Somoza Silva, un 
Así, como miles de sus compatriotas, inició los trámites para trasladarse al país americano. Se acercó al Consulado General de México en Amberes, Bélgica, para realizar las gestiones pertinentes ${ }^{48}$, en ese tiempo residía en La Panne. Bélgica era un país que Calvo conocía, pues, como ya se indicó, en 1937 había colaborado como secretario particular de Mariano Ruiz-Funes, quien en ese tiempo se desempeñaba como embajador en Bélgica ${ }^{49}$.

El traslado a México resultó largo y penoso. El 8 de febrero de 1940 embarcó en el puerto de Liverpool en el vapor Orbita rumbo a la Habana, Cuba. Como era de esperarse, la falta de dinero sólo le permitió pagar un boleto de tercera clase ${ }^{50}$. El trayecto de La Habana a Veracruz lo hizo en el vapor Siboney. Arribó al puerto mexicano de Veracruz el 16 de marzo de $1940^{51}$ y se trasladó al Distrito Federal en ferrocarril ${ }^{52}$. Para realizar esta travesía contó con la ayuda del Servicio de Evacuación de Refugiados Españoles (SERE).

En México, Calvo fue admitido como inmigrante con el carácter de asilado político por un año, con la posibilidad de renovar su permiso. En julio de 1940 solicitó su naturalización al gobierno mexicano y le fue concedida ${ }^{53}$. La situación laboral en el país de asilo no fue fácil para este jurista, ya que pasó un año sin trabajo, hasta que consiguió colocarse en el Fondo de Cultura Económica, gracias a la recomendación de José Medina Echavarría y Manuel Martínez Pedroso ${ }^{54}$, dos viejos conocidos con los que coincidió en los servicios diplomáticos españoles durante el tiempo de la Segunda República.

En México se reunió con Mariano Ruiz-Funes ${ }^{55}$, con el que colaboró hasta la muerte de este catedrático universitario. Después del fallecimiento de su mentor, Calvo aceptó un puesto como funcionario en la Organización de Naciones Unidas, dentro de la Comisión Económica Para América Latina (CEPAL) y trasladó su residencia a Chile ${ }^{56}$.

\section{Julián Calvo y la masonería}

Calvo sabía que su actuación al lado del bando republicano lo había convertido en blanco de la persecución franquista y decidió salir del país que lo vio nacer ${ }^{57}$. El tiempo y

escritor español que había llegado a México en 1939 y a quien mencionó ante las autoridades migratorias mexicanas como su referencia en ese país.

48 AGN, Secretaría de Gobernación, Siglo XX, Departamento de Migración, Españoles, Caja 38, Expediente 40. Julián Calvo Blanco.

49 Entrevista.

50 Entrevista.

51 Véase su expediente en la Biblioteca del INAH, Archivo del Comité Técnico de Ayuda a los Republicanos Españoles, Expediente 5455, Calvo Blanco, Julián.

52 Entrevista.

53 AGN, Secretaría de Gobernación, Siglo XX, Departamento de Migración, Españoles, Caja 38, Expediente 40. Julián Calvo Blanco.

54 Entrevista.

55 Además de discípulo de Mariano Ruiz-Funes fue su secretario personal. Blasco Gil y Saorín Pérez, Las universidades, 2014, 13.

56 Entrevista. Su faceta como intelectual lo llevó a pertenecer a la Academia Mexicana de Ciencias Penales y a la Academy of American Franciscan History. Es autor de tratados y artículos en publicaciones americanas y europeas. Como muchos de sus compatriotas, también incursionó en la traducción y elaboró reseñas bibliográficas. Cfr. Sánchez Casado, Los altos grados de la masonería, 441.

57 Por el mismo jurista se sabe que la última vez que salió de España fue el 27 de enero de 1939. Antes de instalarse en México vivió en Perpignan, París, Bruselas, La Panne (Bélgica) y La Habana, Cuba. Cfr. ADGCPPP, Expedientes de Calvo Blanco, Julián y Vergara Flores, Eliana y su expediente en el Archivo del Comité Técnico de Ayuda a los 
las atrocidades cometidas por el gobierno liderado por Franco contra los seguidores de la Segunda República confirmaron que su decisión de exiliarse fue lo más sensato.

Lo anterior al considerar que el levantamiento armado franquista se respaldó por una copiosa legislación que "proporcionó el marco jurídico que reguló la persecución y castigo de aquellos a quienes se consideró enemigos del bando nacional”.58. Entre estos instrumentos jurídicos destacan la Ley de Responsabilidades Políticas (LRP) y la Ley para la Represión de la Masonería y el Comunismo (LRMC)59. Cabe resaltar que estas dos leyes se complementaban ya que los procesados por el Tribunal Especial para la Represión de la Masonería y el Comunismo (TERMC) también eran sometidos a expediente de responsabilidades políticas, "correspondiendo a los Tribunales de esta jurisdicción imponer la sanción económica" ${ }^{\circ 0}$.

En 1940 se proclamó la Ley para la Represión de la Masonería y el Comunismo, un instrumentó legal hecho a la medida para identificar, procesar, sentenciar y castigar a aquellos seguidores de la Segunda República a los que se acusó de masones o comunistas; aunque no resultó extraño que a los masones se les procesara por ambos delitos.

En la introducción de la Ley para la Represión de la Masonería y el Comunismo se establecía que los dos factores que habían contribuido más perniciosamente a la decadencia de España eran las "sociedades secretas de todo orden y las fuerzas internacionales de índole clandestina”. ${ }^{61}$ Consideraba a la masonería como la más importante de las sociedades secretas y "entre las que, sin constituir una sociedad secreta propiamente, se relacionan con la masonería y adoptan sus métodos al margen de la vida social, figuran las múltiples organizaciones subversivas y adoptan en su mayor parte asimiladas y unificadas por el comunismo" ${ }^{2}$. Así pues, para los franquistas, masones y comunistas eran los principales enemigos de España y a su persecución se dedicaron con tenacidad. También se buscaba difundir la existencia de una alianza entre judaísmo y masonería y se propagó la idea del enemigo judeo-masónico como elemento de cohesión de la sociedad española ${ }^{63}$.

En el artículo primero de la LRMC se estableció que constituía "figura de delito, castigado conforme a las disposiciones de la presente Ley, el pertenecería a la masonería, al comunismo y demás sociedades clandestinas a que se refieren los artículos siguientes". El gobierno franquista se permitió un margen legal para añadir a la masonería y al comunismo "las ramas o núcleos auxiliares que juzgue necesario y aplicarles entonces las mismas disposiciones de esta Ley debidamente adaptadas" ${ }^{64}$.

\footnotetext{
Republicanos Españoles, en Biblioteca del INAH.

Martínez Chávez, "Juristas masones”, 366.

Para más información sobre estas leyes y su aplicación a los masones españoles véase Martínez Chávez, "Juristas masones".

60 Manuel Álvaro Dueñas, ““Por ministerio de ley y voluntad del caudillo”. La jurisdicción especial de responsabilidades políticas (1939-1945)" (Tesis doctoral, Departamento de Historia Contemporánea, Universidad Autónoma de Madrid, 1997), 168.

61 Véase la Ley de 1 de marzo de 1940 sobre represión de la masonería y el comunismo. En Boletín Oficial del Estado 62.

62 Ley de 1 marzo de 1940

63 Sobre este tema véase Javier Domínguez Arribas, El enemigo judeo-masónico en la propaganda franquista (19361945) (Madrid: Marcial Pons, 2009).

64 Ley de 1 marzo de 1940, Pág. 1537.
} 
Como era de esperarse, en el cuerpo de la LRMC se determinó a quien se le podía considerar masón. Así pues, el artículo cuarto estableció:

Son masones todos los que han ingresado en la masonería y no han sido expulsados o no se han dado de baja de la misma o no han roto explícitamente toda relación con ella, y no dejan de serlo aquéllos a quienes la secta ha concedido su autorización, anuencia o conformidad, bajo cualquier forma o expediente, para aparentar alejamiento de la misma ${ }^{65}$.

Las penas a las que se podía sentenciar a masones y comunistas se establecieron en los artículos quinto y sexto. En el artículo quinto se plasmó que "los delitos de masonería y comunismo definidos en el artículo cuarto, serán castigados con la pena de reclusión menor”. Pero, si se daba el caso de que concurriera alguna circunstancia agravante la pena sería de reclusión mayor. Las circunstancias agravantes para los masones eran:

[...] haber obtenido alguno de los grados del dieciocho al treinta y tres, ambos inclusive, o el haber tomado parte en las asambleas de la asociación masónica internacional y similares, o en las asambleas nacionales del gran oriente español, de la gran logia española o de otras cualesquiera organizaciones masónicas residentes en España o el haber desempeñado otro cargo o comisión que acredite una especial confianza de la secta hacia la persona que la recibiób.

Esta fue la estructura institucional que se puso en movimiento para localizar a Julián Calvo Blanco cuando lo identificaron como defensor de la Segunda República y masón. La historia inició cuando el Ministerio de Gobernación, a través de la Dirección General de Seguridad, División de Investigación Social, inició una averiguación sobre sus antecedentes masónicos. Por la documentación que sobre él se conserva en el Centro Documental de la Memoria Histórica se sabe que perteneció a la logia Thader número 90 de los valles de Murcia y que en 1940 fue denunciado como masón ante las autoridades franquistas por varios masones que se retractaron ante el TERMC ${ }^{67}$. Con esta información se le formó el proceso número 217 ante el juzgado número dos del TERMC, por el delito de masonería, esto en marzo de $1945^{68}$.

El mismo día en que inició su proceso sumario se solicitó al jefe de policía de Murcia que hiciera llegar al juzgado la residencia y el domicilio de Calvo Blanco. Para 1945 el encartado ya había puesto mucha distancia de por medio y el comisario murciano sólo atinó a mencionar que de las gestiones que se habían practicado resultaba que se encontraba en "ignorado paradero" y que era posible que se localizara en Suiza ${ }^{69}$. La ignorancia del paradero del jurista prófugo era total, puesto que para la fecha aludida se encontraba ya en otro continente.

$65 \quad$ Ley de 1 marzo de 1940.

66 Artículo sexto de la Ley de 1 marzo de 1940.

67 CDMH, Legajo 50-B, Expediente 20. Expediente personal de Julián Calvo Blanco. Contiene un informe positivo sobre sus actividades dentro de la masonería.

68 CDMH, Tribunal Especial para la Represión de la Masonería y el Comunismo (TERMC), Expediente 882. Proceso formado por masonería a Julián Calvo Blanco. Agradezco al doctor Carlos Francisco Martínez Moreno su generosidad al proporcionarme copia de este documento.

69 CDMH, TERMC, Expediente 882, Proceso formado por masonería a Julián Calvo Blanco. 
El juez al recibir esta respuesta de Murcia decidió seguir el proceso y solicitar al director general de prisiones que comunicara al juzgado si se encontraba Calvo en alguna de las prisiones del Estado. Como no podía ser de otra manera, la respuesta a esta solicitud resultó negativa. El juzgador también envió un oficio al director de seguridad para que se procediera a su busca y captura, además de solicitar que se le requiriera por medio del Boletín Oficial del Estado para que se presentara al juzgado.

No tuvieron éxito ninguna de las gestiones del juez de la causa para localizar a Calvo y, el 11 de junio de 1945, determinó que, por ignorarse su paradero, no presentarse ante el juzgado y, considerando que de los hechos que constaban en el sumario resultaban indicios racionales de su criminalidad, se acordaba su procesamiento en rebeldía y se decretó su prisión provisional. Además, determinó que se remitiera el proceso al Tribunal de Responsabilidades Políticas (TRP) para que Calvo respondiera por cualquier responsabilidad política a que se hubiera hecho acreedor ${ }^{70}$.

La propuesta de la pena realizada por el juez de la causa fue de reclusión menor y "accesorias correspondientes". Una vez realizada la propuesta de la pena consideró concluido el sumario y lo pasó al fiscal para su calificación. El fiscal declaró estar de acuerdo con los autos del procesamiento, con el de rebeldía y con el que declaraba terminado el sumario. Así, el veintiuno de noviembre de 1945 se decretó el archivo provisional del sumario, "en tanto el encartado se presente o sea habido" ${ }^{11}$.

Los años pasaron y las autoridades franquistas no dejaron de intentar localizarlo y apresarlo. La respuesta reiterada era que su situación no había variado, seguía en paradero desconocido y fuera de España. La última actuación que consta en su proceso corresponde a $1962^{72}$, año en que continuaba Calvo radicado en América.

Cabe mencionar que Calvo no llegó sólo a México, fue parte de una oleada de cientos de juristas que se trasladaron a América buscando escapar de la violencia en Europa. Entre los estudiosos del derecho que pertenecieron a la masonería y que asentaron su residencia en México, ya fuera definitiva o temporal, se cuentan profesores universitarios ${ }^{73}$, abogados litigantes ${ }^{74} \mathrm{y}$ algunos licenciados en derecho que se dedicaron a diversas actividades, entre ellas la política. Aquí se pueden citar los nombres de Álvaro Pascual-Leone Forner ${ }^{75}$ o Ángel Galarza Gago; a este último se le procesó por el delito de masonería y, al igual que Calvo Blanco, fue condenado en rebeldía por el TERMC, "como autor de un delito consumado de

7 CDMH, TERMC, Expediente 882, Proceso formado por masonería a Julián Calvo Blanco.

71 CDMH, TERMC, Expediente 882, Proceso formado por masonería a Julián Calvo Blanco.

72 CDMH, TERMC, Expediente 882, Proceso formado por masonería a Julián Calvo Blanco.

73 Sobre este tema véase Martínez Chávez, "Juristas masones", 365-384.

74 Los abogados españoles exiliados en México pudieron ejercer su profesión, en algunos casos siguiendo un procedimiento relativamente fácil. Se tienen noticias del caso del doctor José Alejo Cassinello López, quien ingresó a tierras mexicanas por el puerto de Veracruz en junio de 1939. A su llegada a Veracruz un funcionario mexicano le preguntó si contaban con documentos que avalaran sus estudios en España, el doctor Cassinello López le mostró el título de abogado y el funcionario le estampó un sello con el águila mexicana que decía "válido para ejercer la profesión en México”, con cuya autorización pudo ejercer la abogacía en el país. Entrevista a Emilio Cassinello Aubán, Madrid, octubre de 2010.

75 CDMH, legajo 117-B, Expediente 16. Expediente personal de Álvaro Pascual-Leone Forner. Nombre simbólico "Vicente Peris", Logia Germanies de Valencia. También se le formó proceso por el TERMC, Legajo 148, Expediente 7365 y TERMC, Expediente 14521. 
masoneria [sic] y comunismo, con la concurrencia de solas [sic] circunstancias agravantes a la pena de treinta años de reclusión mayor" ${ }^{6}$.

Las penas impuestas por el TERMC no sólo se limitaban al castigo del cuerpo, se hacían extensivas a otros ámbitos, en este caso también se sentenció a Galarza Gago a la “interdicción civil” y a la inhabilitación absoluta extensiva, para ocupar "cargos en entidades subvencionadas y Empresas concesionarias, gerencias y consejos de administración en Empresas privadas, así como cargos de confianza mando y dirección de las mismas- 77 .

Otro jurista con el que Calvo compartió la pasión por el derecho penal, la vida universitaria, el exilio en América y pertenecer a la masonería, fue Luis Jiménez de Asúa. El catedrático de derecho penal en las aulas madrileñas se exilió en Argentina, pero mantuvo una estrecha relación profesional y personal con los estudiosos del derecho que decidieron permanecer en México. Jiménez de Asúa también fue procesado por el TERMC. Lo sentenciaron el 16 de septiembre de 1941 a la pena de treinta años de reclusión mayor, y al igual que a Galarza Gago, se le sumó a esta pena la accesoria de interdicción civil, "inhabilitación absoluta extensiva, además, a cargos en entidades subvencionadas y empresas concesionarias, gerencias y consejos de administración en empresas privadas, así como cargos de confianza, mando y dirección de las mismas” ${ }^{7}$.

Esta pena se le impuso al catedrático de derecho "por los delitos comprobados de comunismo y masonería-. Al considerar el Tribunal que desde su cátedra y en sus actuaciones forenses y políticas propugnó siempre "por el más exaltado marsismo [sic], disolvente y extremista-; además, se consideró que -advenida la Guerra desempeñó embajadas ante países extranjeros cooperando en pro de las tendencias acusadamente comunistas de los llamados gobiernos a que representaba”79. A los ojos de los franquistas, Jiménez de Asúa, además de masón, resultó un activo militante comunista, de ahí la gravedad de la sentencia que se dictó en su proceso ${ }^{80}$.

Ante este escenario, no resulta extraño que los masones y las organizaciones de masones buscaran salir de España debido a las diversas iniciativas de Franco y sus seguidores para acabar con ellos ${ }^{81}$. Se trata de toda una estructura institucional que atacaba desde diferentes flancos. Se crearon leyes especiales que tipifican como delito la pertenencia a la masonería y se establecieron penas severas para aquellos que eran condenados por este delito, sin contar con los otros procesos que se les podían formar a los seguidores de la República, como los que integraba el Tribunal de Responsabilidades Políticas ${ }^{82}$.

76 En CDMH, TERMC, Expediente 213, Expediente personal de Ángel Galarza Gago.

77 CDMH, TERMC, Expediente 213, Expediente personal de Ángel Galarza Gago.

78 CDMH, legajo 116-B, expediente 7 y legajo 401-B, expediente 7. Expediente personal de Luis Jiménez de Asúa. Según esta documentación se le asignó el nombre simbólico "Carrara” y perteneció a la Logia Dantón número 7 , de Madrid. Obtuvo el grado masónico $3^{\circ}$ (maestro masón).

79 CDMH, legajo 116-B, expediente 7 y legajo 401-B, expediente 7. Expediente personal de Luis Jiménez de Asúa.

80 De reciente defensa es la tesis de Enrique Roldán Cañizares, "Luis Jiménez de Asúa: un jurista en el exilio" (Tesis de doctorado en Derecho, Universidad de Sevilla, 2018).

81 Sobre el Tribunal Especial para la Represión de la Masonería y el Comunismo puede verse el libro de Guillermo Portilla, La consagración del derecho penal de autor durante el franquismo. El Tribunal especial para la represión de la masonería y el comunismo (Granada: Comares, 2009).

82 Para mayores informes sobre el funcionamiento de estos tribunales se puede consultar la investigación de Álvaro 
Así, después de la salida de España fue necesario buscar la reorganización de los hermanos dispersos y ayudar a aquellos que se encontraban en peligro. En México fueron varias las peticiones que llegaron al general Lázaro Cárdenas, entonces presidente de la república mexicana, para ayudar a los hermanos en peligro, principalmente a los que se encontraban en Francia ${ }^{83}$. De la documentación que se remitió a Cárdenas se puede inferir que los masones mexicanos seguían de cerca la suerte de los españoles en desgracia, ya que una petición remitida al presidente en julio de 1940 mencionaba a 800 hermanos masones que se encontraban en París ${ }^{84}$.

La gran mayoría de los españoles que se exiliaron en México se instalaron en la Ciudad de México, incluidos los masones. En ese espacio urbano encontraron el respaldo de la Gran Logia Valle de México. El apoyo se concretó, entre otras cuestiones, en el establecimiento de trámites y plazos para regularizar su situación ante las autoridades masónicas, pero teniendo en cuenta las circunstancias especiales que se derivaron de la Guerra Civil y la pérdida de la documentación que comprobaba su pertenencia a la masonería.

Una forma más de regularizar su situación fue afiliarse a logias mexicanas, lo que fue bien visto por las autoridades masónicas españolas pues consideraron que serviría para estrechar lazos fraternales con los hermanos mexicanos. Carlos Francisco Martínez sostiene que esto debió obedecer a "que ya se realizaban iniciaciones y regularizaciones de

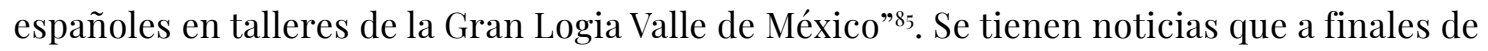
1941 el número de masones exiliados en México era de un centenar y que muchos de los que estaban en Chile y Cuba también tenían planes de trasladarse a México ${ }^{86}$.

Los vestigios de la vida de Julián Calvo permiten conocer un poco más sobre la relación de la masonería mexicana y la española en el exilio. En la entrevista que Calvo dio en 1979 mencionó que llegó a México siendo masón, pues se había afiliado a la masonería en España en $1932^{87}$. Al llegar a tierras mexicanas prosiguió con sus actividades masónicas, "hasta tal

Dueñas, "Por ministerio de ley".

83 La Gran Logia Valle de México se dirigió al titular del ejecutivo mexicano para solicitar su apoyo para que un grupo de refugiados españoles pudieran llegar a México ya que en República Dominicana no los habían recibido. En el documento mencionan que ofrecían su ayuda para distribuir a estos refugiados en el país. Cabe resaltar que no habla de apoyar sólo a los hermanos masones, la ayuda que ofrecen es para los refugiados españoles en general, no se circunscribe sólo a los masones. Este documento fue enviado por Raúl Cordero Amador, Gran Maestro de la Logia Valle de México, al presidente de México el día 8 de julio de 1940. En AGN, fondo Lázaro Cárdenas, Caja 908, 546.6/2012-14, Legajo 2.

84 Esta solicitud la realizó Generoso Canales, Gran Maestro de la Gran Logia Unida “La Oriental Peninsular”. Cfr. AGN, Fondo Lázaro Cárdenas, Caja 908, 546.6/2012-14, legajo 2. Solicitud enviada a Lázaro Cárdenas para el traslado de masones españoles a México.

85 Véanse los trabajos de Carlos Francisco Martínez Moreno, "Prensa masónica española en México. Grande Oriente Español en Exilio. Primera Época (1940-1947)”, en Gibraltar, Cádiz, América y la Masonería. Constitucionalismo y libertad de prensa, 1812-2012 (Zaragoza: Centro de Estudios Históricos de la Masonería Española, Gobierno de Gibraltar, 2014), tomo I, 395-396; "La Gran Logia "Valle de México" durante la Segunda República Española, 1931-1939”, en Cultura Masónica, La historia tiene la palabra. II República española y masonería 75 años después 6, no. 19 (2014): 115-150; y "Masonería española en el exilio de México. Masones españoles regularizados y afiliados en logias bajo la jurisdicción de la Gran Logia Valle de México, 1920-1959”, en La masonería española, represión y exilios (Zaragoza: Centro de Estudios Históricos de la Masonería Española, Departamento de Educación Cultura y Deporte del Gobierno de Aragón, 2010), tomo I, 211-230.

86 Pere Sánchez Ferré, La masonería y los masones españoles del S. XX. Los pasos perdidos, prólogo de José Antonio Ferrer Benimeli (Barcelona: MRA Ediciones, 2012), 242.

87 En el proceso que se le formó por el TERMC se menciona que "La logia "THADER" No 9o de los valles de Murcia, efectuó la iniciación del profano JULIAN CALVO BLANCO, durante el primer trimestre de 1.934; conforme consta 
punto [dice] que los altos grados que yo tengo, los debo al Supremo Consejo de México”. Al momento de la entrevista ostentaba el grado 33 del Rito Escocés Antiguo y Aceptado. Según el propio entrevistado, en México su labor como masón fue muy activa, "tanto en las obediencias mexicanas, como en las españolas”. Por ejemplo, en México participó en la constitución de la asociación civil Grande Oriente Español, en $1942^{88}$.

Este jurista dejó testimonio sobre la ayuda que recibió de los hermanos mexicanos, al mencionar que cuando llegó a México encontró acogida en las obediencias mexicanas de la Gran Logia "Valle de México" desde el mismo día que arribó. También siguió activo en las obediencias españolas y fue requerido en 1978 para hacerse cargo de la reorganización de los altos grados de la masonería en España. Mediante una votación internacional, el Supremo Consejo del grado 33 de España, exiliado en México, le transfirió los poderes a España y el 4 de julio de 1978 instaló el Supremo Consejo en España, del que fue Gran Comendador ${ }^{89}$.

Galo Sánchez calificó de extraordinaria la labor de Calvo Blanco al frente del Supremo Consejo del Grado 33, ya que "a diferencia de otros hombres del exilio, supo integrarse, sin fisuras, en los nuevos rumbos que tomaba España”. Para Sánchez Casado esto se facilitó por el carácter tolerante de Calvo, por su inquietud cultural y la capacidad para afrontar con sentido común las relaciones humanas ${ }^{90}$. Escasos años estuvo Calvo en el ejercicio de este importante puesto, debido a que, como ya se mencionó, murió en 1986.

Después de este breve recorrido por la vida de Julián Calvo Blanco es posible considerar que la masonería jugó un papel trascendental en su existencia, ya que tuvo contacto y recibió apoyo de sus integrantes al quedar huerfano de padre y durante la experiencia del exilio. En su edad temprana encontró respaldo y protección en Mariano Ruiz-Funes García, un masón español a quien Calvo estuvo unido hasta la desaparición física de Ruiz-Funes. Es posible que su acercamiento a la masonería se diera también de la mano de este catedrático. Más aún, el ingreso de Calvo como profesor universitario se dio con el apoyo de Ruiz-Funes y varios de los cargos que desempeñó en su vida se encuentran unidos al viejo profesor. Incluso, en el proceso que le formó el Tribunal Especial para la Represión de la Masonería y el Comunismo se menciona que era "lugarteniente de Ruiz-Funes"

Como es sabido, al perder la Guerra Civil los seguidores de la Segunda República española se vieron en la necesidad de escapar de las represalias franquistas. La gran mayoría salió de España y se instaló en territorio francés; no obstante, el inicio de la Segunda Guerra Mundial y las complicadas condiciones de vida que tenían en Francia, y en Europa, obligaron a miles de exiliados a buscar refugio en América. Aquí aparece en escena otro masón que resultó vital para Calvo Blanco, el presidente mexicano Lázaro Cárdenas del Río. Este mandatario abrió las puertas de su país a miles de españoles que buscaban escapar de la violencia en Europa, iniciativa que salvaría la vida de cientos de masones que pudieron instalarse en México, entre ellos Julián Calvo Blanco.

en la página 10 del Boletin Secreto de la Gran Logia Española núm. 3, correspondiente al mes de julio del año expresado”. Cfr. CDMH, TERMC, Expediente 882. Proceso formado por masonería a Julián Calvo Blanco

88 Esta información puede consultarse en Martínez Moreno, "Prensa masónica".

89 Entrevista a Julián Calvo Blanco, 101-104. Sobre los masones en el exilio puede verse Sánchez Ferré, La masonería.

$90 \quad$ Sánchez Casado, Los altos grados de la masonería, 440-441.

91 CDMH, TERMC, Expediente 882, Proceso formado por masonería a Julián Calvo Blanco. 


\section{Fuentes}

Archivos Históricos

Archivo de la Dirección General de Costes de Personal y Pensiones Públicas (Clases Pasivas) - ADGCPPP.

Archivo General de la Administración - AGA.

Archivo General de la Nación de México - AGN.

Archivo Histórico de la Junta para Ampliación de Estudios - AHJAE.

Biblioteca del Instituto Nacional de Antropología e Historia (México) - Biblioteca INAH.

Boletín Oficial del Estado - BOE.

Centro Documental de la Memoria Histórica - CDMH.

Gaceta de Madrid - GM.

Instituto Nacional de Antropología e Historia - INAH.

\section{Bibliografía}

Álvaro Dueñas, Manuel, "Por ministerio de ley y voluntad del caudillo". La jurisdicción especial de responsabilidades políticas (1939-1945). Tesis de doctorado, Departamento de Historia Contemporánea, Universidad Autónoma de Madrid, 1997.

Blasco Gil, Yolanda y Tomás Saorín Pérez. Las universidades de Mariano Ruiz-Funes: La lucha desde el exilio por la Universidad perdida. Murcia: Universidad de Murcia, 2014.

Calvo Blanco, Julián. “Semblanza de Mariano Ruiz-Funes”. En Derecho consuetudinario y economía popular de la provincia de Murcia. Murcia: Biblioteca Básica Murciana, 1983.

Cebreiros Álvarez, Eduardo. “Rodríguez Muñoz, José Arturo (1899-1955)”. En Diccionario de catedráticos españoles de derecho. 1847-1943. Madrid: Universidad Carlos III de Madrid, 2013.

Domínguez Arribas, Javier, El enemigo judeo-masónico en la propaganda franquista (19361945). Madrid: Marcial Pons, 2009.

Gracia Arce, Beatriz. "Mariano Ruiz-Funes: intelectual y político (1923-1953). Aportación a la modernización del sistema liberal-democrático en España y proyección internacional de su obra”. Tesis de doctorado en Filosofía, Universidad de Murcia, 2013. 
Martínez Chávez, Eva Elizabeth. "Juristas masones del exilio republicano español en México”. En Masonería y sociedades secretas en México. Coordinado por José Luis Soberanes Fernández y Carlos Francisco Martínez Moreno. Ciudad de México: UNAM, Instituto de Investigaciones Jurídicas, 2018, 365-384.

Martínez Chávez, Eva Elizabeth. "Ruiz-Funes García, Mariano (1889-1953)”. En Diccionario de catedráticos españoles de derecho (1847-1943). Madrid: Universidad Carlos III de Madrid, 2012.

Martínez Moreno, Carlos Francisco, "Prensa masónica española en México. Grande Oriente Español en Exilio. Primera Época (1940-1947)”. En Gibraltar, Cádiz, América y la Masonería. Constitucionalismo y libertad de prensa, 1812-2012. Zaragoza: Centro de Estudios Históricos de la Masonería Española, Gobierno de Gibraltar, 2014.

Martínez Moreno, Carlos Francisco. "La Gran Logia "Valle de México" durante la Segunda República Española, 1931-1939”. Cultura Masónica, La historia tiene la palabra. II República española y masonería 75 años después 6, no. 19 (2014).

Martínez Moreno, Carlos Francisco. "Masonería española en el exilio de México. Masones españoles regularizados y afiliados en loguas bajo la jurisdicción de la Gran Logia Valle de México, 1920-1959”. En La masonería española, represión y exilios. Zaragoza: Centro de Estudios Históricos de la Masonería Española, Departamento de Educación Cultura y Deporte del Gobierno de Aragón, 2010.

Martínez Neira, Manuel y Julián Gómez de Maya. "Reverte Moreno, Antonio (1905-1981)”. En Diccionario de catedráticos españoles de derecho. 1847-1943. Madrid: Universidad Carlos III de Madrid, 2016.

Mezger, Edmund. Tratado de Derecho Penal. Traducido por José Arturo Rodríguez Muñoz. Madrid: Editorial Revista de Derecho Privado, 1935.

Portilla, Guillermo. La consagración del derecho penal de autor durante el franquismo. El Tribunal especial para la represión de la masonería y el comunismo. Granada: Comares, 2009.

Roldán Cañizares, Enrique, "Luis Jiménez de Asúa: un jurista en el exilio”. Tesis de doctorado en Derecho, Universidad de Sevilla, 2018.

Ruiz-Funes García, Mariano. Progresión histórica de la pena de muerte en España. Madrid: Editorial Revista de Derecho Privado, 1934.

Sánchez Ferré, Pere. La masonería y los masones españoles del S. XX. Los pasos perdidos. Prólogo de José Antonio Ferrer Benimeli. Barcelona: MRA Ediciones, 2012. 


\section{Entrevistas}

Entrevista realizada a Emilio Cassinello Aubán por Eva Elizabeth Martínez Chávez, Madrid, octubre de 2010 .

Entrevista realizada a Julián Calvo por Concepción Ruiz-Funes, el día 5 de mayo de 1979 y anexo realizado por Enriqueta Tuñón los días 30 de noviembre y 3 de diciembre de 1981. 